\title{
Niche shifts and local competition between two coral reef fishes at their geographic boundary
}

\author{
Andrew J. Limbourn ${ }^{\mathrm{A}, \mathrm{B}}$, Geoffrey P. Jones ${ }^{\mathrm{A}, \mathrm{C}}$, Philip L. Munday ${ }^{\mathrm{A}}$ \\ and Maya Srinivasan ${ }^{\mathrm{A}}$ \\ A School of Marine and Tropical Biology, and ARC Centre of Excellence for Coral Reef Studies, \\ James Cook University, Townsville, Qld 4811, Australia. \\ ${ }^{B}$ Current address: School of Animal Biology, University of Western Australia, 35 Stirling Highway, \\ Crawley, WA 6009, Australia. \\ ${ }^{\mathrm{C}}$ Corresponding author. Email: geoffrey.jones@jcu.edu.au
}

\begin{abstract}
Competition theory predicts that, when resources are limiting, interacting species should differ more in resource use where they co-occur, compared with where they do not (resource partitioning). The damselfishes Dascyllus aruanus and D. melanurus provide a useful test of this prediction because they exhibit largely allopatric geographic ranges that overlap near Port Moresby, Papua New Guinea. To test whether this species pair exhibited responses in resource use that were consistent with competition theory, the depth distributions, coral substrata and diet of each species at allopatric and sympatric locations were compared. Where sympatric, the frequency of co-occurrence was examined and foraging ranges and diet on corals where the species do and do not co-occur were compared. Contrary to expectations, the species were more similar in depth, habitat use and diet in the sympatric region. Within this location, they sometimes co-existed in the same coral shelters, but much less often than would be expected with random assortment. Where they did co-exist, their diets converged. D. melanurus exhibited restricted foraging ranges and consumed smaller prey in the presence of D. aruanus, but not vice versa. It was concluded that niche shifts along different resource axes at the geographic boundary are explained both by large-scale constraints in resource availability and local-scale competitive interactions.
\end{abstract}

Additional keywords: convergence, Dascyllus, resource partitioning, sympatry.

\section{Introduction}

Early ecological theory was based on a premise that divergence among closely related species over evolutionary time occurs as a mechanism for reducing inter-specific competition (Arthur 1982; Schoener 1982; Keddy 1989). According to competition theory, the coexistence of competing species is achieved largely through resource partitioning (Colwell and Fuentes 1975; Diamond 1978; Schoener 1982). However, in apparent contradiction, optimal foraging theory predicts the opposite pattern decreased specialisation and convergence among species as a consequence of competition (Stephens and Krebs 1986; Robinson and Wilson 1998). Empirical studies show a range of responses, with pairs of potentially competing species exhibiting divergence, convergence or little change in resource use when and where they come into contact. The effects of inter-specific competition can also become evident at a range of spatial scales, from local scale interactions among individuals (Hixon 1980, 2006; Schoener 1983) to interactions that establish the limits of a species' geographic range (Wethey 2002; Case et al. 2005; Geber and Eckhart 2005; Morin and Chuine 2006). Assessing the relative importance of the different outcomes of competition, and the spatial scales over which they operate, must begin with the description of patterns of resource use both where putative competitors co-occur and where they do not.
The importance of competition in bringing about habitatpartitioning has been particularly controversial in the literature on coral reef fishes (Sale 1980, 1991; Doherty and Williams 1988; Jones 1991). Early researchers assumed that competition for space was universal, but were divided over whether competition led to changes in resource use (e.g. Smith and Tyler 1972, 1975; Robertson and Lassig 1980) or whether reef fish were competitive equals, successfully exploiting the same limited resources (e.g. Sale 1977, 1980). History has shown that different competitive outcomes can occur in different situations. There is a growing body of evidence that inter-specific competition between coral reef fishes can lead to habitat partitioning (Ebersole 1985; Robertson and Gaines 1986; Robertson 1996; Bay et al. 2001), reduce individual growth rates (Forrester et al. 2006) or reduce the abundance of one or both of the competing species in particular habitats (Schmitt and Holbrook 1999; Srinivasan et al. 1999; Munday et al. 2001; Munday 2004). Convergence in resource use can also occur under conditions of limited resource availability because species can be forced to consume the same prey (Holbrook and Schmitt 1989). Other studies have found no detectable effects of competition on distribution, abundance or resource use (Doherty 1983; Jones 1988), whereas Munday et al. (2001) found a whole spectrum of competitive responses within a single guild of coral-dwelling gobies. 
The accumulating evidence suggests that ecological responses to competition in reef fishes can occur along a range of resource axes, including depth, micro-habitat use and diet. To date most studies have focussed on a single resource, most commonly, micro-habitats or coral substrata (e.g. Ebersole 1985; Robertson and Gaines 1986; Srinivasan et al. 1999; Bay et al. 2001; Munday et al. 2001). Given that species do not necessarily partition all their critical resources, focussing on just one resource may lead to an under-estimate of the importance of resource partitioning. In addition, although local scale interactions among reef fishes have been well studied, the larger-scale implications, such as the potential for competition to limit overlap at species borders, have not been examined.

One approach to identifying the potential for resource partitioning among pairs of species is to compare patterns of resource use in regions or habitats of sympatry (where they occur together) and allopatry (where they are found apart) (Schluter and McPhail 1992; Schluter 2000; Hixon 2006). If resource partitioning arises from the depletion of shared resources, then we should observe a shift in resource use between locations where species are sympatric and allopatric. For example, Robertson and Gaines (1986) found that where similar species of surgeonfish co-occur, they exhibit reduced overlap in both habitat and diet, indicating that resource partitioning is potentially occurring. A full description of the potential extent of the ecological shift of both potential competitors requires that a range of resources be examined for each species, both where they are together and where they are not. Although testing among alternative hypotheses that may explain niche shifts ultimately requires measures of resource availability and experimental manipulations, the description of patterns in resource use is the first step in identifying appropriate hypotheses.

The coral-dwelling fishes of the genus Dascyllus (family Pomacentridae) have a distribution and ecology particularly suitable for exploring the potential relationship between competition and resource partitioning. Individuals of small Dascyllus species are typically restricted to single coral colonies (e.g. Sale 1972; Jones 1987; Forrester 1990; Booth 1995; Holbrook et al. 2000) where they have access to shelter and can exploit passing planktonic food. Inter-specific interactions for limited resources at the level of the individual coral colony could be particularly intense, and may lead to either a subdivision of coral resources, or if co-existing in the same coral, a subdivision of food resources (Coates 1980; Shpigel 1982). Schmitt and Holbrook (1999) have demonstrated asymmetric competition between $D$. flavicauda and $D$. aruanus in Tahiti, the former reducing the survival of the latter in coral colonies where they co-exist.

The primary goal of the present study was to examine preliminary evidence for niche divergence between two species of Dascyllus by comparing patterns of resource use in sympatry and allopatry at two spatial scales. The humbug damsel (Dascyllus aruanus) and the convict damsel (D. melanurus) are sister species with very similar ecologies (Godwin 1995; McCafferty et al. 2002). They exhibit parapatric geographic distributions that facilitate a study of ecological partitioning at the species boundaries. D. aruanus is common on the Great Barrier Reef and D. melanurus is common in Papua New Guinea. There is also a small region of overlap in southern Papua New Guinea, where both species occur in relatively high abundance, sometimes together in the same coral heads, but more often than not in separate corals. To examine potential niche shifts, we measured resource use along multiple resource axes, including depth, coral micro-habitat, frequency of co-existence in the same coral colonies, foraging ranges and diet. On the basis of competition theory, it can be predicted that there will be lower overlap in resource use within the small region of sympatry as a result of resource partitioning or ecological displacement of an inferior competitor. Similarly, there should be lower overlap in food and space resources in coral heads where they co-occur, compared with those where they are found in single-species colonies. Alternatively, if patterns of resource use are constrained by geographic or local changes in resource availability, convergence in resource use may be expected where the two species occur together.

\section{Materials and methods}

Study sites

Resource use in Dascyllus aruanus and D. melanurus were examined on the Great Barrier Reef and in Papua New Guinea between December 2002 and March 2003. To compare patterns of resource use in regions of allopatry and sympatry, each species was examined at two of three geographic locations, with two island sites sampled at each location: (1) D. aruanus was studied at Lizard Island (South and Palfrey Islets) $\left(14^{\circ} 41^{\prime} \mathrm{S}: 145^{\circ} 27^{\prime} \mathrm{E}\right)$ on the northern Great Barrier Reef, Australia, where D. melanurus is absent. (2) D. melanurus was studied at Restorf and Schumann Islands, Kimbe Bay $\left(5^{\circ} 30^{\prime} \mathrm{S}: 150^{\circ} 05^{\prime} \mathrm{E}\right)$ in West New Britain Province, Papua New Guinea, where D. aruanus has not been recorded. (3) Both Dascyllus species were examined at Lion and Loloata Islands in Bootless Bay $\left(9^{\circ} 32^{\prime} \mathrm{S}: 147^{\circ} 17^{\prime} \mathrm{E}\right)$, southern Papua New Guinea. The largely allopatric distributions of these two species rarely overlap, although both have also been recorded from the Philippines (McCafferty et al. 2002).

To examine the degree of co-existence and patterns of resource use on a local scale, observations focussed on the two sites at Bootless Bay. Bootless Bay is a large open bay, $\sim 30 \mathrm{~km}$ south-east of Port Moresby, which is sheltered from oceanic swells by the Papuan Barrier Reef, $\sim 7.5 \mathrm{~km}$ off the mainland coast. The islands in Bootless Bay are surrounded by a well developed fringing reef that grades into a gentle sandy slope containing many scattered individual patch reefs to a maximum depth of $\sim 15-20 \mathrm{~m}$. Many of these patch reefs consist of one to a few individual branching coral species (mainly Acropora spp. and Pocillopora spp.). Groups of either D. aruanus or D. melanurus, or mixed species groups, were usually associated with a single coral head in patch reef habitats.

\section{Depth and micro-habitat}

To compare resource use of $D$. melanurus and $D$. aruanus among and within geographic locations, divers used a random search technique to census all coral colonies occupied by $D$. melanurus, D. aruanus or both species. Sampling was restricted to a depth range of $1-20 \mathrm{~m}$ at the two sites at each geographic location. A minimum of 100 corals occupied by Dascyllus spp. were sampled at each site. For each coral head inhabited by Dascyllus, divers recorded depth, the species of coral inhabited and the total number of D. melanurus and D. aruanus present. 
Patterns of habitat use were quantified by calculating the proportion of all individuals of each species in each depth stratum (divided into $2 \mathrm{~m}$ depth intervals) or the proportion associated with each coral type (identified to species level). Resourcepartitioning theory predicts that interacting species will be more similar to one another where they occur alone, compared with where they co-exist. To quantify degrees of similarity in depth and habitat use, we calculated pairwise Renkonen Percentage Similarity $(P)$, as recommended by Wolda (1981). Among geographic locations, the similarity between species where each is found alone (Lizard Is. for D. aruanus and Kimbe Bay for D. melanurus) was compared with their similarity where they cooccurred (Bootless Bay). Because no differences were observed among the two sites within locations, data were pooled for presentation.

\section{Diet}

In order to compare the diet of the two species where they occurred alone and where they co-existed, at least 16 whole social groups were collected from coral colonies at each of the three geographic locations. Within the location of sympatry, all individuals of both Dascyllus species were collected from eight coral heads where each species was found alone, and also from a further eight coral heads shared by the two species. Collections of single and mixed colonies were made from the same areas within the same depth strata to avoid the potential effects of site-specific differences in diet. Renkonen Percent Similarity $(P)$ values were calculated to compare the diets of the two species in sympatry and allopatry, and where sympatric, when each species was on coral heads alone and when each was in the presence of the other Dascyllus species.

All fish were collected in the early afternoon between 1200 and 1700 hours. Fish were collected at this time of the day because Dascyllus are diurnal feeders and therefore more likely to have full stomachs, with minimal digestive deterioration. Collections were made using clove oil and a fine-mesh net $(2 \mathrm{~mm})$. Individuals were anaesthetised using clove oil solution and collected using a small hand net. Following capture, all fish were killed by placing them on ice and then stored in buffered $10 \%$ seawater formalin before examination.

The prey composition and lengths at least 50 prey items were measured from each individual's stomach. In the laboratory, the small sac-like stomach was removed from the body cavity, cut in two, and the contents placed in a Petri dish. The stomach contents were diluted with a small amount of seawater, agitated to prevent stratification and spread evenly over the surface area of the dish. Percentage cover of the stomach items was obtained by scoring the identity of food items on the centre of 50 randomly positioned cross hairs. Dietary items were classified to taxonomic Class, and, where possible, Order. Items were initially placed into one of 22 categories that were later limited to 9 broad taxonomic categories that each contributed to $>5 \%$ of the diet. Dietary analysis of both species was restricted to individuals $>25 \mathrm{~mm}$ in total length.

Analysis of covariance (ANCOVA) was carried out using STATISTICA (StatSoft Inc., Tulsa, OK) to compare prey sizes consumed when in conspecific and congeneric groups, both for
D. aruanus and D. melanurus. The body size of each individual fish was included as a covariate to control for the possible effects of body size on the size of prey consumed. Homogeneity of slopes, the interactions between the main effect and the covariate, were tested first in the ANCOVA procedure. Where the slopes were homogenous, the interaction term was pooled and the ANCOVA recalculated.

\section{Patterns of co-occurrence}

The degree of co-existence of D. aruanus and D. melanurus at the scale of individual coral heads was examined at Bootless Bay only. To test the hypothesis that the frequency of co-occurrence was less than would be expected by random assortment, given the overall population size of each species, the abundance of each species was censused in 370 coral heads on the fringing reefs of Loloata and Lion Islands. For each coral head, the absolute abundance of each species of Dascyllus was recorded. If there was a random mixing of the two species, then more mixed species groups are expected as social groups increase in size. To test the relationship between total group size and species co-occurrence, the binomial distribution was used to calculate the expected probability of getting mixed species groups of different sizes based on the combined absolute abundance of each species from both sites. The expected frequency of mixed groups for each social group size was then plotted against the actual observed distribution of mixed species groups for all group sizes.

\section{Foraging area and position}

To examine whether inter-specific interactions influence the foraging area or position of individuals on coral heads, the foraging movements of individuals of each species were measured, both on coral colonies occupied by each species separately and on corals where they co-occurred at Bootless Bay. Observations were restricted to individuals of mid-size range (25-50 mm total length) and to similar sized coral heads containing at least five individuals of each species, with five replicate coral heads for each treatment (five for $D$. aruanus alone, five for $D$. melanurus alone and five for D. aruanus $+D$. melanurus).

Once suitable colonies were located, the observer took up a position adjacent to the coral colony and perpendicular to the direction of current. This was the optimal angle to view withincolony foraging behaviour because individuals vary in the extent to which they forage up-current from the coral head. Individuals foraging further up-current were assumed to get 'first choice' of incoming prey items, as observed in other studies (Coates 1980; Booth 1995). The observer plotted the relative position from shelter (height above the substratum and horizontal distance away from shelter) of one individual fish per colony every $10 \mathrm{~s}$ for a total of $10 \mathrm{~min}$ ( 60 observations) to give an estimate of a potential foraging range size. The total area covered over these forays was calculated to the nearest $0.1 \mathrm{~m}$ of a metre by mapping the cloud of peripheral data points. The mean foraging area was compared between conspecific and heterospecific groups. A Student's $t$-test, using STATISTICA, was used to determine if the foraging area differed for Dascyllus aruanus and D. melanurus when in the presence $v$. absence of the other species (Booth 1995). 


\section{Results}

Comparison of geographic locations of sympatry and allopatry

\section{Depth}

There was no evidence for divergence in the depth distributions of D. aruanus and D. melanurus in the region of sympatry, although each species exhibited a substantial geographic difference in their depth profiles (Fig. 1). The two species overlapped broadly in their depth distributions at the location of sympatry (Bootless Bay, Southern Papua New Guinea (PNG)) and were more similar to one another here $(P=66.8 \%)$ than at their allopatric locations $(P=6.4 \%)$. D. melanurus occupied a narrow depth range in northern PNG where $D$. aruanus was absent, with $\sim 80 \%$ of all fishes found from only $0-2 \mathrm{~m}$ depth. At the sympatric location, it exhibited a wider and deeper depth distribution $(0-8 \mathrm{~m})$. Most individuals of $D$. aruanus were found between 4 and $14 \mathrm{~m}$ at Lizard Island, whereas in southern PNG most

\section{(a) Lizard Island}

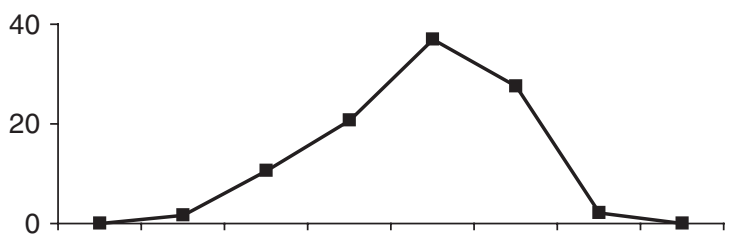

(b) Bootless Bay

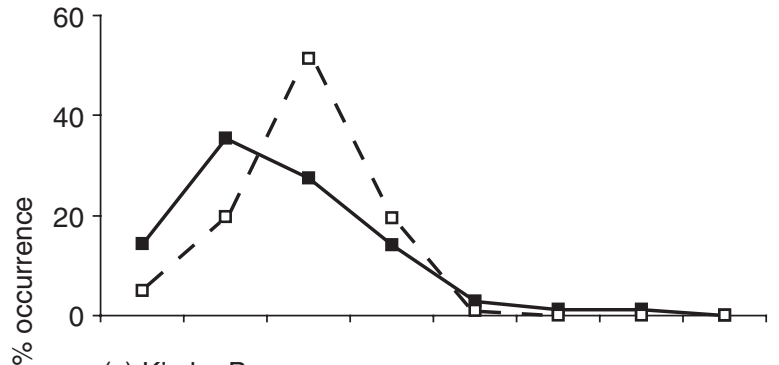

(c) Kimbe Bay

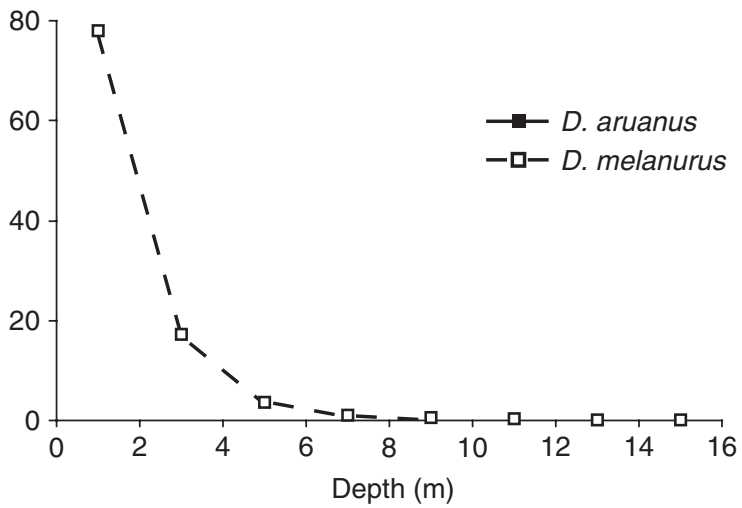

Fig. 1. Comparison of the depth distributions of D. melanurus and D. aruanus between: allopatric $((a)$ D. aruanus: Lizard Island, northern Great Barrier Reef; $(c) \sim D$. melanurus: Kimbe Bay, northern Papua New Guinea); and (b) sympatric (Bootless Bay, southern Papua New Guinea) geographic locations. The depth-frequency distributions are calculated using $2 \mathrm{~m}$ depth intervals. individuals were found in shallower water $(2-8 \mathrm{~m})$. Although there was considerable overlap in the depth distributions of the two species in southern PNG, D. melanurus tended to be more abundant in the shallower depths $(0-4 \mathrm{~m})$.

\section{Micro-habitat use}

Both Dascyllus aruanus and D. melanurus exhibited substantial differences in the coral species occupied at each geographic location (Fig. 2), which likely reflects differences in the coral species present at the two locations. As with depth distributions, patterns of micro-habitat use were most similar at the sympatric locations $(P=57.1 \%)$, compared with the allopatric locations $(P=16.2 \%)$. At southern PNG, both species were commonly associated with Porites cylindrica and Millipora tenulla, but they also used a range of other branching corals (Fig. 2). At the northern Great Barrier Reef (GBR) location, D. aruanus occupied a relatively restricted range of corals, primarily Pocillopora damicornis and Montipora digitata. In contrast, D. melanurus tends to have a much broader pattern of habitat use where it occurs

(a) Lizard Island

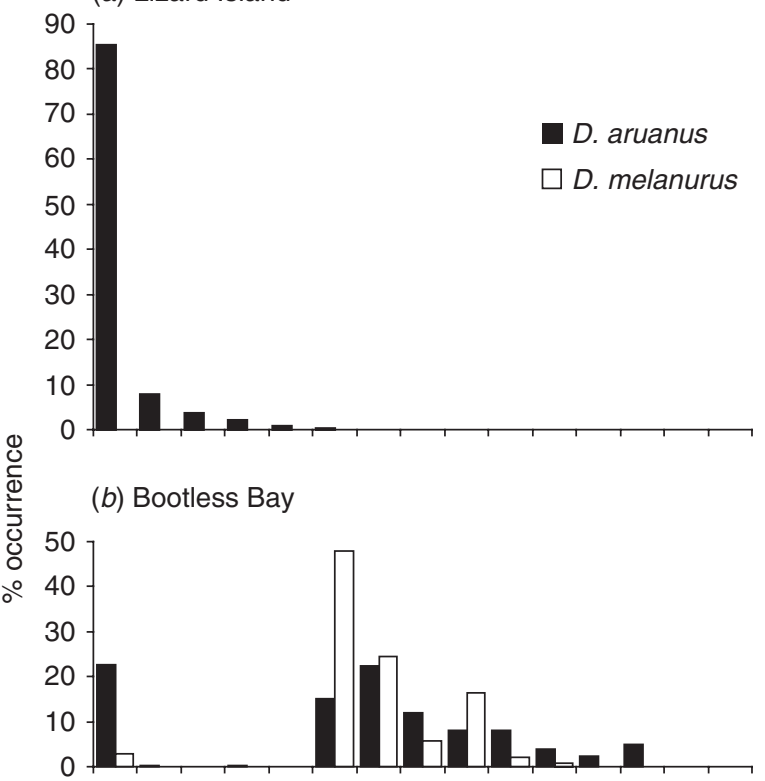

(c) Kimbe Bay

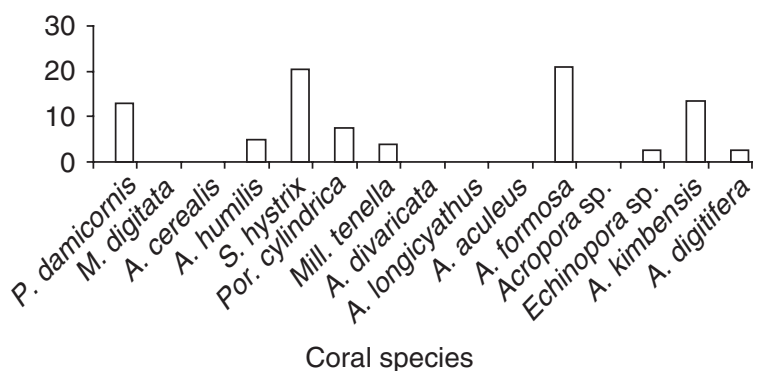

Fig. 2. The observed distribution of D. aruanus and D. melanurus among different coral substrata from: allopatric ( $(a) D$. aruanus: Lizard Island, northern Great Barrier Reef; $\sim$ D. melanurus: $(c)$ Kimbe Bay, northern Papua New Guinea) and (b) sympatric (Bootless Bay, southern Papua New Guinea) geographic locations. 
(a) Lizard Island

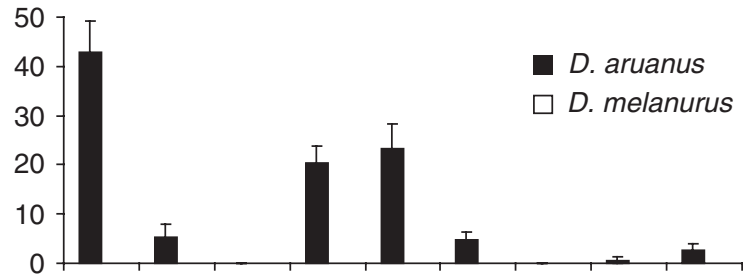

(b) Bootless Bay

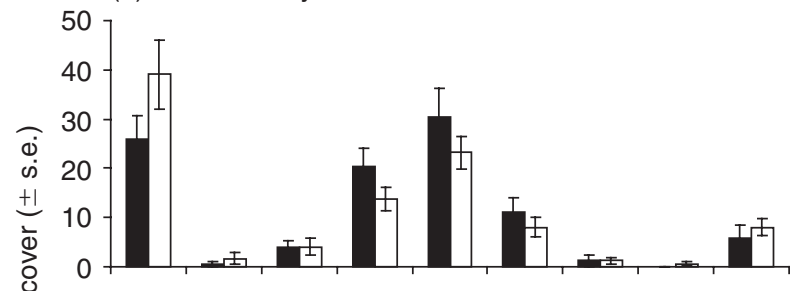

(c) Kimbe Bay

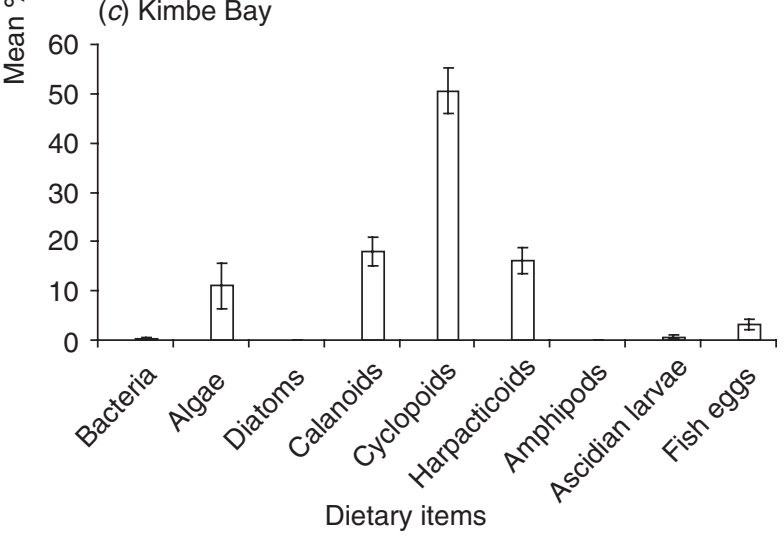

Fig. 3. Mean percent cover of major dietary items in the stomachs of D. melanurus and D. aruanus from (a) allopatric (D aruanus: Lizard Island, northern Great Barrier Reef; $(c) \sim D$. melanurus: Kimbe Bay, northern Papua New Guinea) and (b) sympatric (Bootless Bay, southern Papua New Guinea) geographic locations.

at Kimbe Bay. Here it was commonly associated with Seriatopora hystrix, Acropora formosa, A. kimbeensis and P. damicornis. Although the use of coral substrata by the two species was similar at the sympatric location, D. aruanus was associated with $P$. damicornis more often than $D$. melanurus. In contrast, D. melanurus was more often associated with $P$. cylindrica.

\section{Diet similarity}

As with depth and micro-habitat use, the diets of the two fish species were more similar at the sympatric location $(P=82.3 \%)$, compared with the allopatric locations $(P=55.6 \%)$. Both $D$. melanurus and D. aruanus were found to have consumed a high proportion of cyanobacteria in Bootless Bay, accounting for their greater similarity at this location (Fig. 3). In contrast to depth and micro-habitat use, the diets of the two Dascyllus species were generally more similar to one another and more conservative among locations (Fig. 3). Cyclopoid and calanoid copepods formed an important component of the diet of both species at all locations (Fig. 3). D. melanurus exhibited the largest change in diet between locations, with cyanobacteria (a)

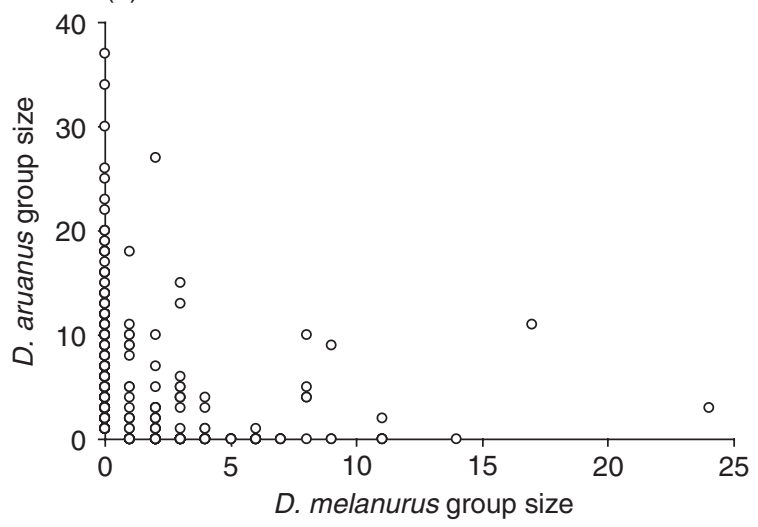

$(b)$

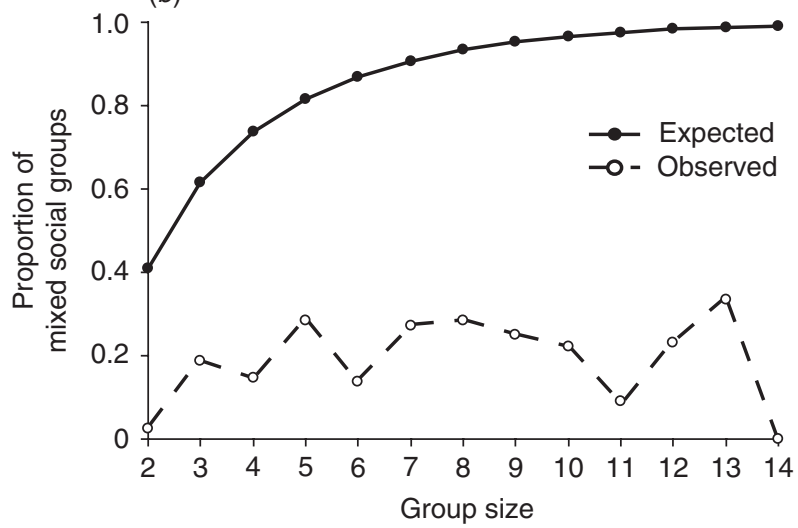

Fig. 4. (a) Number of D. melanurus and D. aruanus in social groups on coral colonies at the sympatric geographic location (Bootless Bay, southern Papua New Guinea). (b) The distribution of mixed species groups within Bootless Bay, southern Papua New Guinea. •: proportion of social groups predicted to contain both species of Dascyllus assuming random assortment (binomial theory). $\circ$ : observed proportion of mixed social groups of different size.

dominating the diet in Bootless Bay, but it was rarely consumed at Kimbe Bay.

\section{Resource use within the region of sympatry}

\section{Patterns of co-occurrence}

There is strong evidence for the partitioning of habitat on the scale of individual coral heads (Fig. 4a). Although both species were commonly associated with similar coral micro-habitats at similar depths, the composition of groups occupying a single coral was not a random assortment of individuals. Out of a total of 370 coral heads occupied by one or both species, 315 were occupied by a single Dascyllus species (D. aruanus 69\%, D. melanurus $31 \%$ ), with only 55 coral heads populated by both fish species. Coral heads occupied by high numbers of $D$. aruanus were never associated with high numbers of D. melanurus, even though large single-species groups ( $>10$ individuals) were common (Fig. 4a).

The proportion of social groups containing both $D$. aruanus and $D$. melanurus was substantially lower than that predicted by chance for social groups of all sizes (Fig. 4b). Furthermore, 


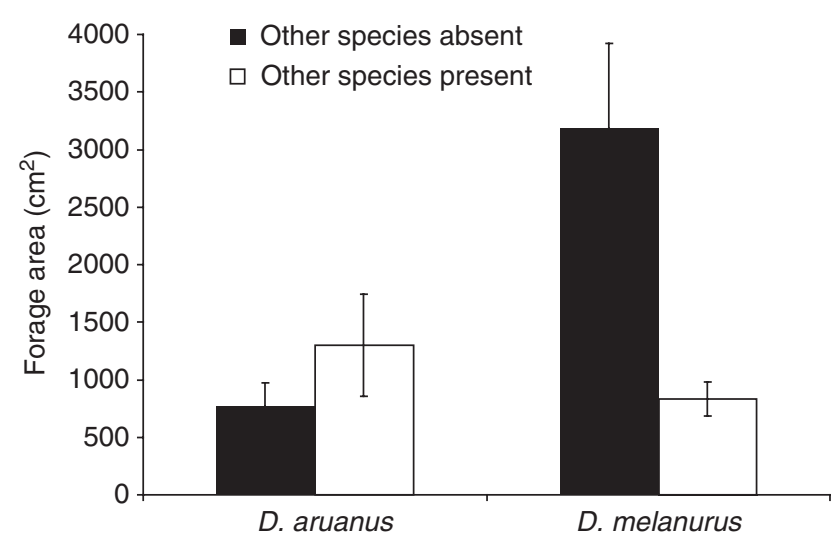

Fig. 5. Mean 2-dimensional foraging area of D. melanurus and D. aruanus when in single-species groups on coral heads compared with mean foraging areas of individuals in mixed species groups. Error bars \pm 1 s.e.

there was no apparent increase in the proportion of mixed species groups as group size increased, as would be predicted if individuals were randomly colonising coral heads. $D$. aruanus and D. melanurus rarely co-occurred within corals, regardless of the total number of individuals inhabiting a coral colony.

\section{Foraging range and position}

In the presence of $D$. aruanus, D. melanurus was apparently restricted to a significantly smaller foraging area than where it was found in single species groups (two-tailed $t$-test, $t=5.24$, d.f. $=17, P<0.01$, data normally distributed) (Fig. 5). D. melanurus foraged over a large area, usually up-current from the coral shelter when in conspecific groups. However, in the presence of $D$. aruanus, the foraging range was restricted to the immediate vicinity of the home coral head. In contrast, there was no significant difference in the foraging area of $D$. aruanus when alone or in the presence of $D$. melanurus $(t=1.13$, d.f. $=13, P=0.27)$ (Fig. 5). When together, most individuals of $D$. aruanus tended to forage further up-current than $D$. melanurus individuals.

\section{Prey composition}

Despite a high level of dietary similarity between the two Dascyllus species at Bootless Bay, there were differences in their diets when in conspecific groups compared with mixed species groups (Fig. 6). Both D. melanurus and D. aruanus consumed lower proportions of cyanobacteria and higher proportions of cyclopoid copepods in the presence of the other species, compared with the diets of fish from single species groups (Fig. 6). The similarity in the diet of $D$. melanurus, when alone compared with when co-occurring with $D$. aruanus was only $71.2 \%$, representing a substantial intra-specific shift in diet. Likewise, the average $D$. aruanus diet when alone was $78.6 \%$ similar to diets of $D$. aruanus from mixed species groups.

The intra-specific shifts in food consumption were not explained by partitioning of diets between the two fish species, but rather convergence. The diets of the two species where they co-habited coral colonies were actually more similar to one another $(P=93.1 \%)$ than the diets of each species in the presence $v$. absence of the congener. (a) D. aruanus

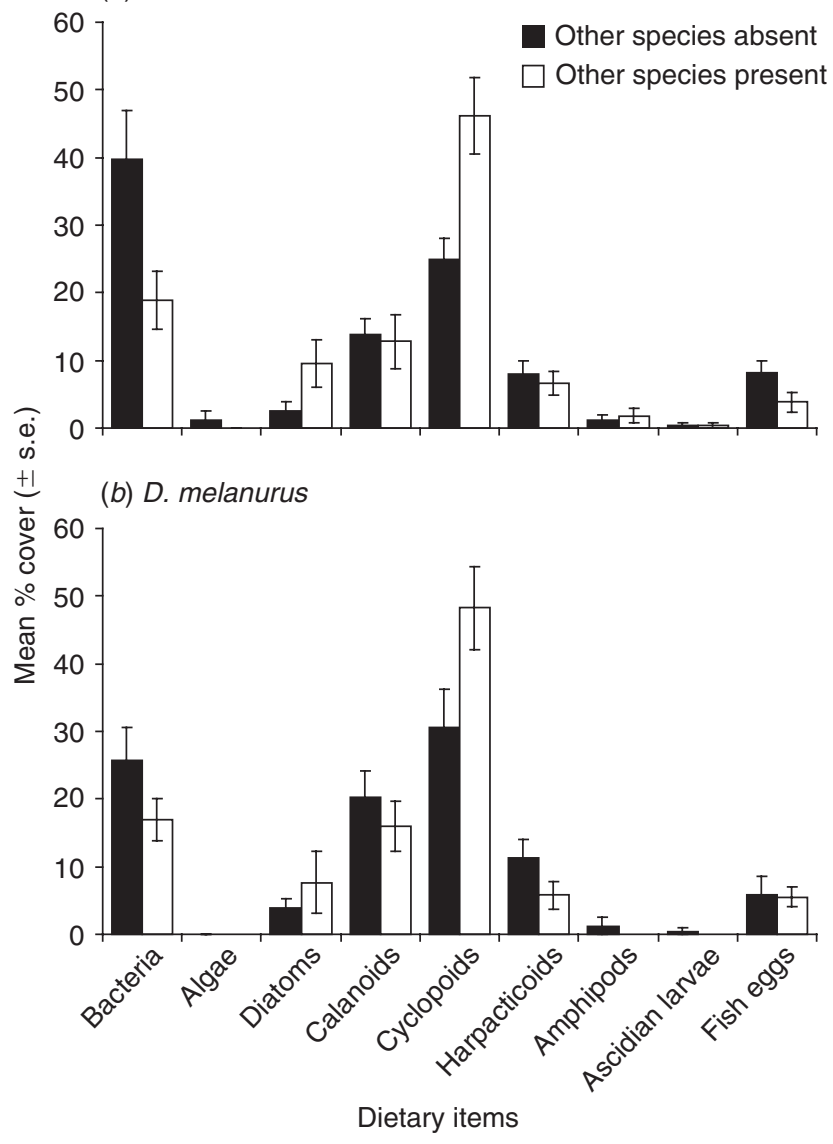

Fig. 6. (a) Comparison of mean percent cover of major dietary items in stomachs of $D$. aruanus when in the presence (open bars) and absence (filled bars) of $D$. melanurus. (b) Comparison of mean percentage cover of major dietary items in stomachs of $D$. melanurus when in the presence (open bars) and absence (filled bars) of $D$. aruanus. Error bars \pm 1 s.e.

\section{Prey size}

There were substantial differences in the size of prey consumed by $D$. melanurus on coral heads with and without D. aruanus (Fig. 7). Where D. melanurus occurred alone, individuals tended to consume larger harpacticoid and calanoid copepods, but the sizes of cyclopoids were similar. Although prey size tended to increase as a function of fish size, analysis of covariance indicated a significant interaction between $D$. melanurus size and the presence or absence of the congener (Table 1). Inspection of the data suggests that this was because $D$. aruanus had a large effect on the size of prey consumed by large D. melanurus, but not small individuals (Fig. 7). That is, larger D. melanurus consumed smaller calanoids in the presence of $D$. aruanus, whereas smaller $D$. melanurus consumed similar sized prey. In contrast, there was no significant effect of the presence of $D$. melanurus on the size of prey consumed by D. aruanus (Fig. 7). Although prey sizes in the three copepod groups increased as a function of fish length, analysis of covariance did not distinguish these relationships on the basis of the presence or absence of $D$. melanurus (Table 2 ). As a consequence of the changes in the prey sizes consumed by $D$. melanurus in the 


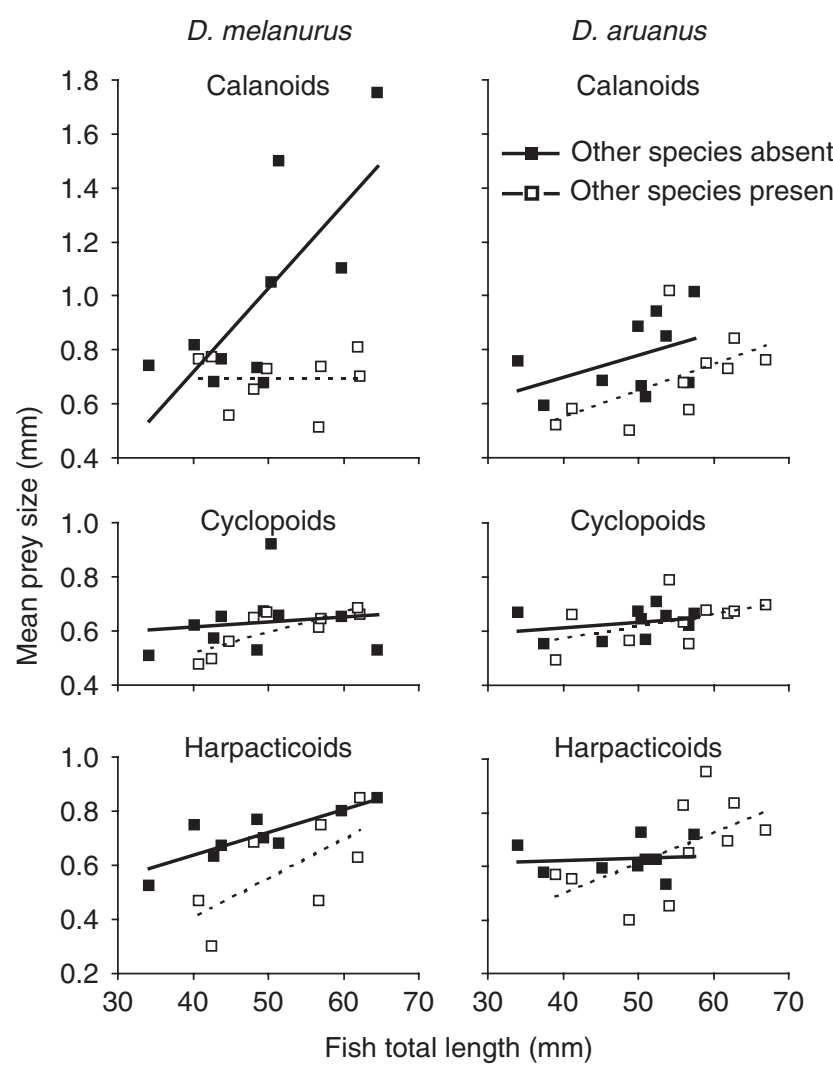

Fig. 7. Relationships between total length of $D$. melanurus (left column) or D. aruanus (right column) and the mean prey size of three copepod groups (calanoids, cyclopoids and harpacticoids). In each case, separate relationships are shown for mean prey size in the presence $(\square)$ and absence ( $\square$ ) of the congener.

Table 1. Analysis of covariance for the effect of the presence and absence of $D$. aruanus on the relationship between body size (total length) to calanoid copepod prey size for $D$. melanurus

Dependent variable: prey size. Covariate: body size (D. melanurus total length). Treatment: presence/absence of $D$. aruanus. $*$ : significant at $P<0.05$

\begin{tabular}{lcrccc}
\hline Source & $\begin{array}{c}\text { Type III sum of } \\
\text { squares }\end{array}$ & d.f. & Mean square & $F$ & $P$ \\
\hline Treatment & 0.244 & 1 & 0.244 & 4.050 & 0.061 \\
Body size & 0.250 & 1 & 0.250 & 4.158 & 0.058 \\
T $\times$ BS & 0.355 & 1 & 0.355 & 5.910 & $0.027^{*}$ \\
Total & 1.927 & 19 & & & \\
\hline
\end{tabular}

presence of $D$. aruanus, there was greater overlap in the range of prey sizes consumed by the two species where they co-occurred.

\section{Discussion}

There is evidence that the congeneric and morphologically very similar sister species, Dascyllus aruanus and D. melanurus, compete for shelter and planktonic food in the region of sympatry. However, the effects are complex and most evident at the scale of individual coral shelter sites. The hypothesis that
Table 2. Analysis of covariance for the effect of the presence and absence of $D$. melanurus on the relationship between body size (total length) to calanoid copepod prey size for D. aruanus

Dependent variable: prey size. Covariate: body size (D. aruanus total length). Treatment: presence/absence of $D$. melanurus. ${ }^{*}$ : significant at $P<0.05$

\begin{tabular}{lcrccc}
\hline Source & $\begin{array}{c}\text { Type III sum of } \\
\text { squares }\end{array}$ & d.f. & Mean square & $F$ & Sig. \\
\hline Treatment & 0.073 & 1 & 0.073 & 4.010 & 0.061 \\
Body size & 0.111 & 1 & 0.111 & 6.086 & $0.025^{*}$ \\
T $\times$ BS & 0.001 & 1 & 0.001 & 0.044 & 0.837 \\
Total & 0.447 & 19 & & & \\
\hline
\end{tabular}

inter-specific competition may induce resource partitioning or ecological character displacement on a geographical scale was not supported by the present study and there was no evidence that competition is involved in maintaining the relatively disjunct border between these two damselfishes. In terms of their depth distributions, coral species used as shelter sites and planktonic diet, they appear to be more similar in the sympatric region, which is opposite to the pattern predicted by competition theory. We hypothesise that this convergence in resource use in the region of sympatry is largely explained by greater similarities in resource availability where species co-occur.

Inter-specific competition clearly has the potential to limit species distributions (Wethey 2002; Case et al. 2005; Geber and Eckhart 2005; Morin and Chuine 2006). However, in the case of these two Dascyllus species, the disjunct geographic distributions of the sister taxa probably reflect historic patterns of speciation and constraints on dispersal (Bernardi et al. 2001, 2002; McCafferty et al. 2002), rather than limiting effects of current-day competition on range expansion. The high level of similarity between the two species at Bootless Bay, and the high level of geographic variation within Dascyllus species are most likely to be explained by geographic changes to reef structure and the availability of resources. However, studies of other geographic locations, in combination with resource availability measures, are required to test this hypothesis.

Although geographic convergence in resource use in the sympatric region is unlikely to be explained by competition, it clearly increases the potential for local-scale competitive interactions between the two species. These interactions were manifest as segregation between the two species among coral shelter sites and a convergence in diets where they co-occurred within the same corals. Although the two species had similar ecologies, and overlapped broadly in their depth distributions and use of coral substrata, they rarely formed mixed-species groups. Where they did co-exist, their diets were more similar, even though there was evidence of asymmetric interactions over foraging space and access to planktonic food resources. The presence of $D$. aruanus appears to reduce the foraging area or home range of co-existing individuals of $D$. melanurus. Their presence also appears to reduce the average size of the prey they consume, especially the larger individuals. Neither the foraging ranges nor the prey sizes of $D$. aruanus appeared to exhibit a reciprocal decline in the presence of $D$. melanurus.

The results of the present study suggest that the local effects of inter-specific competition between two closely related species 
may be complex. The interaction between $D$. aruanus and D. melanurus appears to involve niche displacement, segregation and convergence, depending on the scale of focus and resource in question. Among coral heads there was clear evidence of segregation, whereas within coral heads, both displacement and convergence in prey consumption were apparent. Varying responses to competition can depend on the degree to which different resources are limiting (resource availability), the degree of overlap in the fundamental niche of potential competitors and whether or not there is a strong competitive asymmetry among the contestants (Colwell and Fuentes 1975; Underwood 1986, 1988). In the case of Dascyllus, we hypothesise that shelter, food and perhaps other resources are limiting to different degrees. A single coral head may not provide the requisites for survival and/or reproduction for both species. In addition, the presence of two species on a single coral may deplete preferred food resources to the extent that convergence results from both species being forced to consume small, less preferred prey (Stephens and Krebs 1986; Robinson and Wilson 1998). These hypotheses need to be tested by experiments in which inter-specific competition for different resources and competitive asymmetries are measured under controlled conditions.

The potential for intra-specific competition in Dascyllus spp. has been well documented. Experimental manipulations have shown that juvenile growth is often inversely related to population size or density (Jones 1988; Forrester 1990; Booth 1995) and individuals exhibit an increase in growth rates when given supplemental food (Jones 1986; Forrester 1990; Booth 2004). Prey intake can be lower in crowded conditions (Kent et al. 2006) and the size of prey consumed by lower ranked individuals has been shown to increase when larger ranked individuals are removed (Coates 1980). The evidence here that competition extends to inter-species interactions supports the experimental results of Schmitt and Holbrook (1999) who found that the presence of $D$. flavicaudus reduced the population growth of $D$. aruanus on the same coral heads. As in the present study, there was a competitive asymmetry, with $D$. aruanus having a much lower effect on $D$. flavicaudus than vice versa. In our case, $D$. aruanus appeared to be dominant over D. melanurus, which suggests that its position in the competitive hierarchy at any geographic location may depend on which other species are present.

The performance of individuals in single and multi-species groups occupying coral shelter sites is likely to be complex, involving not only competitive interactions over food and shelter, but also the potential benefits of living in groups. Holbrook and Schmitt (2002) found that density dependent mortality in Dascyllus spp. is related to increased predation on individuals in poorer shelter locations (i.e. at the margins of the habitat). Thus, although foraging further from shelter has the potential advantage in terms of access to incoming planktonic prey, this access could come at a cost of a greater chance of being eaten. Whether individuals compete for better foraging sites or better shelter sites may depend on the relative costs and benefits of each, which may differ for different fish species and may also vary over the day-night cycle. Competition for foraging locations may be more important during the day for these diurnal species and competition for shelter may be most important at night, when resting individuals are exposed to nocturnal predators (Holbrook and Schmitt 2002). The ability of different species to exploit preferred foraging positions during the day may depend on a species' susceptibility to diurnal predators, which may give species reaching larger sizes a competitive edge.

The disadvantage of being an inferior competitor may be counter-balanced by the advantages of living in groups, such as predator detection and/or mobbing. Several Dascyllus species preferentially settle with larger conspecifics (Sweatman 1983; Jones 1987) and their survival is often higher if larger conspecifics are present (Jones 1987; Forrester 1990; Booth 1995). Group living may even enhance feeding efficiency at times when food is abundant (Booth 2004). The low frequency of occurrence of multi-species groups may be explained not only by interspecific competition, but also by active selection of coral heads containing conspecifics and active avoidance of other species at settlement. Local-scale differences in habitat selection based on other factors, such as current speed, may also be important (Schmitt and Holbrook 2002).

The present study showed unexpectedly high geographic and local variation in the depth distributions, substratum-use and diets of the two Dascyllus species, which may be independent of competition. Biogeographic variation in patterns of resource use is rarely quantified for coral reef fishes. The extent of the variation in Dascyllus appears to contrast with more specialised species, which have more rigid habitat preferences that appear to determine their large-scale patterns of abundance (Munday 2002). Although Dascyllus are clearly reliant on branching coral for shelter, both species studied here appear to have the flexibility to adjust resource use depending on regional and local conditions. The data suggest that there may be a shift towards shallower depth distributions and use of a greater range of coral substrata from south to north. However, the degree to which large-scale patterns in resource use are controlled by changes in reef profiles, resource diversity and availability, and other factors such as changing fish species composition requires further investigation.

Competition for living space, within and among fish species, was once thought to be a ubiquitous process limiting populations and structuring assemblages on coral reefs. However, despite numerous pairwise studies of potentially competing species, it is clear that when competition is occurring, there is no universal outcome. Given the high diversity of fishes on coral reefs and the numerous ecological niches they occupy, a diversity of responses to competition should not be surprising. The present study highlights the need to focus on the full spectrum of resources and a range of spatial scales over which one species may be affected by another.

\section{Acknowledgements}

Many thanks to the following: Dik Knight and staff at Loloata Island Dive Resort, Port Moresby; Max Benjaman and staff from both the Walindi Plantation Resort and the Mahonia Na Dari Research and Conservation Centre, Kimbe; the staff at Lizard Island Research Station; and V. Montalbano, G. Almany and C. Delacy for their assistance in the field; and three anonymous reviewers. This research was supported by the ARC Centre of Excellence for Coral Reef Studies.

\section{References}

Arthur, W. (1982). The evolutionary consequences of inter-specific competition. Advances in Ecological Research 12, 127-187. 
Bay, L. K., Jones, G. P., and McCormick, M. I. (2001). Habitat selection and aggression as determinants of spatial segregation among damselfish on a coral reef. Coral Reefs 20, 289-300. doi:10.1007/S003380100173

Bernardi, G., Holbrook, S. J., and Schmitt, R. J. (2001). Gene flow at three spatial scales in a coral reef fish, the three-spot dascyllus, Dascyllus trimaculatus. Marine Biology 138, 457-465. doi:10.1007/S002270000484

Bernardi, G., Holbrook, S. J., Schmitt, R. J., Crane, N. L., and Martini, E. (2002). Species boundaries, populations and colour morphs in the coral reef three-spot damselfish (Dascyllus trimaculatus) species complex. Proceedings of the Royal Society of London. Series B. Biological Sciences 269, 599-605. doi:10.1098/RSPB.2001.1922

Booth, D. J. (1995). Juvenile groups in a coral-reef damselfish: densitydependent effects on individual fitness and population demography. Ecology 76, 91-106. doi:10.2307/1940634

Booth, D. J. (2004). Synergistic effects of conspecifics and food on growth and energy allocation of a damselfish. Ecology 85, 2881-2887. doi: $10.1890 / 03-0535$

Case, T. J., Holt, R. D., McPeek, M. A., and Keitt, T. H. (2005). The community context of species' borders: ecological and evolutionary perspectives. Oikos 108, 28-46. doi:10.1111/J.0030-1299.2005.13148.X

Coates, D. (1980). Prey-size intake in humbug damselfish, Dascyllus aruanus (Pisces, Pomacentridae) living within social groups. Journal of Animal Ecology 49, 335-340. doi:10.2307/4292

Colwell, R. K., and Fuentes, E. R. (1975). Experimental studies of the niche. Annual Review of Ecology and Systematics 6, 281-310. doi:10.1146/ ANNUREV.ES.06.110175.001433

Diamond, J. M. (1978). Niche shifts and the rediscovery of interspecific competition. American Scientist 66, 322-331.

Doherty, P. J. (1983). Tropical territorial damselfishes: is density limited by aggression or recruitment? Ecology 64, 176-190. doi:10.2307/1937339

Doherty, P. J., and Williams, D. M. (1988). The replenishment of coral reef fish populations. Oceanography and Marine Biology 26, 487-551.

Ebersole, J. P. (1985). Niche separation of two damselfish species by aggregation and differential microhabitat utilization. Ecology 66, 14-20. doi: $10.2307 / 1941302$

Forrester, G. E. (1990). Factors influencing the juvenile demography of a coral-reef fish. Ecology 71, 1666-1681. doi:10.2307/1937576

Forrester, G. E., Evans, B., Steele, M. A., and Vance, R. R. (2006). Assessing the magnitude of intra- and interspecific competition in two coral reef fishes. Oecologia 148, 632-640. doi:10.1007/S00442-006-0397-0

Geber, M. A., and Eckhart, V. M. (2005). Experimental studies of adaptation in Clarkia xantiana. II. Fitness variation across a subspecies border. Evolution 59, 521-531.

Godwin, J. (1995). Phylogenetic and habitat influences on mating system structure in the humbug damselfishes (Dascyllus, Pomacentridae). Bulletin of Marine Science 57, 637-652.

Hixon, M. A. (1980). Food production and competitor density as the determinants of feeding territory size. American Naturalist 115, 510-530. doi: $10.1086 / 283577$

Hixon, M. A. (2006). Competition. In 'The Ecology of Marine Fishes: California and Adjacent Waters'. (Eds L. G. Allen, D. J. Pondella and M. H. Horn.) pp. 449-465. (University of California Press: Berkeley, CA.)

Holbrook, S. J., and Schmitt, R. J. (1989). Resource overlap, prey dynamics, and the strength of competition. Ecology 70, 1943-1953. doi:10.2307/ 1938124

Holbrook, S. J., and Schmitt, R. J. (2002). Competition for shelter space causes density-dependent predation mortality in damselfishes. Ecology 83, 2855-2868.

Holbrook, S. J., Forrester, G. E., and Schmitt, R. J. (2000). Spatial patterns in abundance of a damselfish reflect availability of suitable habitat. Oecologia 122, 109-120. doi:10.1007/PL00008826

Jones, G. P. (1986). Food availability affects growth in a coral reef fish. Oecologia 70, 136-139. doi:10.1007/BF00377123
Jones, G. P. (1987). Some interactions between residents and recruits in two coral reef fishes. Journal of Experimental Marine Biology and Ecology 114, 169-182. doi:10.1016/0022-0981(88)90136-0

Jones, G. P. (1988). Experimental evaluation of the effects of habitatstructure and competitive interactions on juveniles of two coral reef fishes. Journal of Experimental Marine Biology and Ecology 123, 115-126. doi:10.1016/0022-0981(88)90164-5

Jones, G. P. (1991). Post-recruitment processes in the ecology of coral reef fish populations: a multifactorial perspective. In 'The Ecology of Fishes on Coral Reefs'. (Ed. P. F. Sale.) pp. 294-328. (Academic Press: San Diego, CA.)

Keddy, P. A. (1989). 'Competition.' (Chapman and Hall: London.)

Kent, R., Holzman, R., and Genin, A. (2006). Preliminary evidence on group-size dependent feeding success in the damselfish Dascyllus marginatus. Marine Ecology Progress Series 323, 299-303. doi:10.3354/ MEPS323299

McCafferty, S., Bermingham, E., Quenouille, B., Planes, S., Hoelzer, G., and Asoh, K. (2002). Historical biogeography and molecular systematics of the Indo-Pacific genus Dascyllus (Teleostei: Pomacentridae). Molecular Ecology 11, 1377-1392. doi:10.1046/J.1365-294X.2002.01533.X

Morin, X., and Chuine, I. (2006). Niche breadth, competitive strength and range size of tree species: a trade-off based framework to understand species distribution. Ecology Letters 9, 185-195. doi:10.1111/J.14610248.2005.00864.X

Munday, P. L. (2002). Does habitat availability determine geographical-scale abundances of coral-dwelling fishes? Coral Reefs 21, 105-116.

Munday, P. L. (2004). Competitive coexistence of coral-dwelling fishes: The lottery hypothesis revisted. Ecology 85, 623-628. doi:10.1890/03-3100

Munday, P. L., Jones, G. P., and Caley, M. J. (2001). Interspecific competition and coexistence in a guild of coral-dwelling fishes. Ecology 82, 2177-2189.

Robertson, D. R. (1996). Interspecific competition controls abundance and habitat use of territorial Caribbean damselfishes. Ecology 77, 885-899. doi: $10.2307 / 2265509$

Robertson, D. R., and Lassig, B. (1980). Spatial distribution patterns and coexistence of a group of territorial damselfishes from the Great Barrier Reef. Bulletin of Marine Science 30, 187-203.

Robertson, D. R., and Gaines, S. D. (1986). Interference competition structures habitat use in a local assemblage of coral reef surgeonfishes. Ecology 67, 1372-1383. doi:10.2307/1938693

Robinson, B. W., and Wilson, D. S. (1998). Optimal foraging, specialization and a solution to Liem's paradox. American Naturalist 151, 223-235. doi:10.1086/286113

Sale, P. F. (1972). Influence of corals in the dispersion of the pomacentrid fish, Dascyllus aruanus. Ecology 53, 741-743. doi:10.2307/1934795

Sale, P. F. (1977). Maintenance of high diversity in coral reef fish communities. American Naturalist 111, 337-359. doi:10.1086/283164

Sale, P. F. (1980). The ecology of fishes on coral reefs. Oceanography and Marine Biology 18, 367-421.

Sale, P. F. (1991). 'The Ecology of Fishes on Coral Reefs.' (Academic Press: New York.)

Schluter, D. (2000). Ecological character displacement in adaptive radiation. American Naturalist 156, S4-S16. doi:10.1086/303412

Schluter, D., and McPhail, J. D. (1992). Ecological character displacement and speciation in sticklebacks. American Naturalist 140, 85-108. doi: $10.1086 / 285404$

Schmitt, R. J., and Holbrook, S. J. (1999). Settlement and recruitment of three damselfish species: larval delivery and competition for shelter space. Oecologia 118, 76-86. doi:10.1007/S004420050705

Schmitt, R. J., and Holbrook, S. J. (2002). Spatial variation in concurrent settlement of three damselfishes: relationships with near-field current flow. Oecologia 131, 391-401. doi:10.1007/S00442-002-0893-9

Schoener, T. W. (1982). The controversy over interspecific competition. American Scientist 70, 586-595. 
Schoener, T. W. (1983). Simple models of optimal feeding-territory size: a reconciliation. American Naturalist 121, 608-629. doi:10.1086/284090

Shpigel, M. (1982). Niche overlap among two species of coral dwelling fishes of the genus Dascyllus (Pomacentridae). Environmental Biology of Fishes 7, 65-68. doi:10.1007/BF00011825

Smith, C. L., and Tyler, J. C. (1972). Space resource sharing in a coral reef fish community. Bulletin of the Natural History Museum of Los Angeles County 14, 125-170.

Smith, C. L., and Tyler, J. C. (1975). Succession and stability in fish communities of the dome-shaped patch reefs in the West Indies. American Museum Novitates 2572, 1-18.

Srinivasan, M., Jones, G. P., and Caley, M. J. (1999). Experimental evaluation of the roles of habitat selection and interspecific competition in determining patterns of host use by two anemonefishes. Marine Ecology Progress Series 186, 283-292. doi:10.3354/MEPS186283

Stephens, D. W., and Krebs, J. R. (1986). 'Foraging Theory.' (Princeton University Press: Princeton, NJ.)
Sweatman, H. P. A. (1983). Influence of conspecifics on choice of settlement sites by larvae of two pomacentrid fishes (Dascyllus aruanus and D. reticulatus). Marine Biology 75, 225-229. doi:10.1007/BF00406006

Underwood, A. J. (1986). The analysis of competition by field experiments. In 'Community Ecology: Pattern and Process'. (Eds J. Kikkawa and D. J. Anderson.) pp. 240-268. (Blackwell Scientific Press: Oxford.)

Underwood, A. J. (1988). Design and analysis of field experiments on competitive interactions affecting behaviour of intertidal animals. In 'Behavioral Adaptation to Intertidal Life'. (Eds G. Chelazzi and M. Vannini.) pp. 333-357. (Plenum Press: New York.)

Wethey, D. S. (2002). Biogeography, competition, and microclimate: The barnacle Chthamalus fragilis in New England. Integrative and Comparative Biology 42, 872-880. doi:10.1093/ICB/42.4.872

Wolda, H. (1981). Similarity indices, sample size and diversity. Oecologia 50, 296-302. doi:10.1007/BF00344966

Manuscript received 2 February 2007, accepted 14 November 2007 